\title{
The Investment Portfolio of the Swiss National Bank and its Carbon Footprint
}

\author{
Alain Naef ${ }^{1}$
}

\begin{abstract}
This paper details the nature of the equity holdings of the Swiss National Bank (SNB) and estimates its carbon footprint. By analyzing SNB holdings in the 100 most polluting companies in the world, I find that the share of assets owned by the SNB are responsible for at least a quarter of Switzerland's domestic CO2 emissions. This represents as much as the greenhouse gas emissions of all Swiss households combined or $0.05 \%$ of global greenhouse gas emissions. Using two different estimation methods, I find that the SNB's portfolio generates between 12 and 20 million metric tons of $\mathrm{CO} 2$ per year. This could be reduced by $99.7 \%$ with an investment reallocation of just $2 \%$ of the equity portfolio of the SNB.
\end{abstract}

Keywords: Carbon emissions, financial pollution, asset management, Swiss National Bank.

JEL codes: E5, G11, P18, F31

\footnotetext{
${ }^{1}$ This research was undertaken while a postdoc at UC Berkeley. This research was supported by the SNSF (P2SKP1_181320). I thank Gaurav Gandhi for excellent research assistance. For comments and discussions, I am grateful to Sam Foxall, Ritika Goel, Cécile Hediger, Simon Hinrichsen, Jens van't Klooster, Yasmin Shearmur, Dóra Simon, and participants to the Berkeley research Fika.
} 
The foreign currency portfolio of the Swiss National Bank (SNB) is the third largest for a central bank, following only the People's Bank of China and the Bank of Japan (OMFIF 2019). From 2011 to 2015, the SNB intervened on foreign exchange markets to avoid an appreciation of its currency, part of its inflation targeting mandate. This resulted in the SNB accumulating foreign exchange reserves which were invested in bonds and equities. In this paper I calculate the greenhouse gases (GHG) generated by the firms the SNB partly owns.

100 companies generated $76 \%$ of global GHG and I focus on the 27 of these 100 which the SNB has invested in. Focusing on these 27 companies, I find that the SNB's portfolio generates between 12-20 million metric tons of $\mathrm{CO} 2$ equivalent (tCO2e). This is equivalent to $38 \%$ of Switzerland's total CO2 emissions and as much as all households combined. A reallocation of only $2 \%$ of the equity portfolio would reduce this number by $99.7 \%$.

Scholars have looked at central bank independence and asset management. Klooster and Fontan (2019) have analyzed how the SNB and the European Central bank both strategically invoke an ideal of "market neutrality" to justify their investments. Best (2016) has argued that the role of central banks is more political than they like to show. Central banks do make important political decisions, since a wide variety of purchases would allow them to achieve the objectives spelled out in their monetary policy mandate.

National $\mathrm{CO} 2$ emissions can be measured in different ways. Production-based emissions encompass emissions taking place on the territory of a country; income-based emissions are measured according to the revenue of emission generating activities such as oil extraction ; and consumption-based accounting attributes emissions to the final consumers and is more biased towards advanced countries (Steininger et al. 2016). Here I focus on calculating the scope 3 carbon footprint of the Swiss National Bank. Scope 3 emissions includes both the use of sold products as well as investments of a company (GHG Protocol 2011). As the SNB does not sell any products, its scope 3 carbon footprint includes mainly its investments. The GHG Protocol (2011, p.93) notes that scope 3 emissions should be attributed "based on the company's proportional share of equity" which is the method I use. Scope 3 SNB emissions are then compared with the production-based emissions of Switzerland which are published by the Swiss statistical office.

\section{The portfolio of the SNB}

I focus on the $20 \%$ of the SNB's foreign currency portfolio which is held in equities. The SNB invests in 6700 companies in 40 countries (Maechler and Moser 2019). The dollar equity portfolio is worth approximately $\$ 94 \mathrm{bn}$ and the non-dollar $\$ 68 \mathrm{bn}$. The SNB also invests in corporate and government bonds, but they are not included in my analysis (Figure 1).

The SNB does not invest in banks to avoid conflicts of interests. They also avoid companies "which produce internationally banned weapons, seriously violate fundamental human rights or systematically cause severe environmental damage."2 Even if the SNB affirms to "not engage in any stock selection", it decided against investing in a whole sector (banking) and established exclusion criteria (excluding

\footnotetext{
${ }^{2} \mathrm{SNB}(2015)$.
} 
for example Lockheed Martin, a defense firm). Such choices show that the SNB is not just a "market neutral" investor but makes decisions based on its own political criteria (Klooster and Fontan 2019).

Figure 1 SNB's portfolio
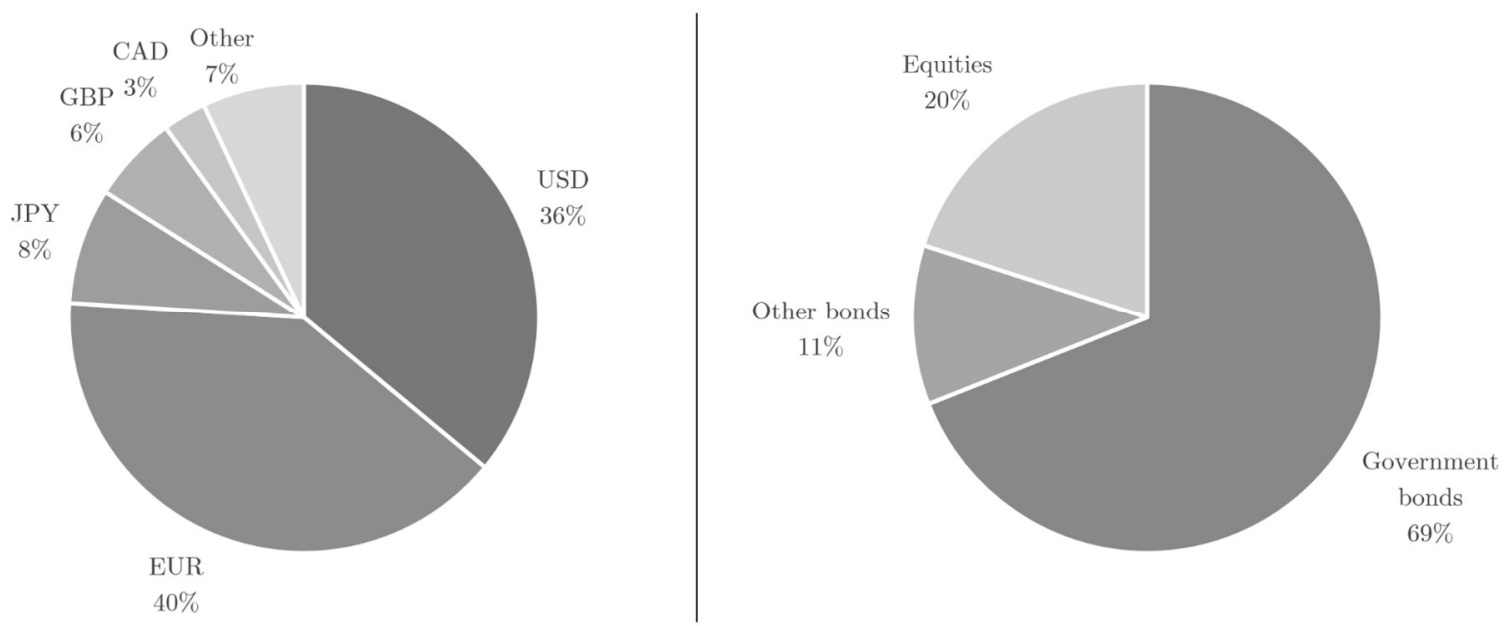

Source: SNB

\section{The SNB's carbon footprint}

I combine firm ownership data with firm GHG emission data. Ownership data comes from Bloomberg. Large US asset holders are obliged to report to the Securities and Exchange Commission (SEC) their position every quarter and the SNB has disclosed its share in US equities. I use two methods to calculate the SNB's carbon footprint, outlined below.

\section{1) Global emissions approach}

First, I rely on GHG emissions as reported in Griffin (2017), who calculates the GHG share of the 100 most polluting companies between 1988 and 2015. I assume that the data for 2019 is in line with values of 1988-2015. While this might not be true for a given company, it should be true on average as global CO2 emissions have been increasing. Results in Table 1 show that the portfolio of the SNB emits at least $0.05 \%$ of global emissions. 2019 emissions were around 43.1 billion (Jackson et al. 2019). ${ }^{3} 0.05 \%$ of 43.1 billion tCO2e would place the SNB's portfolio around 20.25 million tCO2e. This number is $38 \%$ of the latest official overall Swiss GHG emissions of 53.14 million tCO2e. ${ }^{4}$ And as much as every Swiss household combined (19.18 million tCO2e for households vs 20.25 for the SNB portfolio).

\footnotetext{
${ }^{3}$ https://www.globalcarbonproject.org/carbonbudget/19/files/Norway_CICERO_GCB2019.pdf.

${ }^{4}$ https://www.bfs.admin.ch/bfs/fr/home/statistiques/themes-transversaux/mesure-bien-etre/tousindicateurs/environnement/emissions-gaz-effet-serre.assetdetail.10027928.html.
} 
Table 1 SNB GHG share of the 100 most polluting companies

\begin{tabular}{|c|c|c|c|}
\hline Company & $\begin{array}{c}\text { Percentage } \\
\text { of global } \\
\text { GHG }\end{array}$ & $\begin{array}{c}\text { SNB's } \\
\text { company } \\
\text { share }\end{array}$ & $\begin{array}{c}\text { SNB } \\
\text { portfolio } \\
\text { share of } \\
\text { pollution }\end{array}$ \\
\hline ExxonMobil & $1.98 \%$ & $0.40 \%$ & $0.00792 \%$ \\
\hline Royal Dutch Shell & $1.67 \%$ & $0.39 \%$ & $0.00651 \%$ \\
\hline $\mathrm{BP}$ & $1.53 \%$ & $0.36 \%$ & $0.00551 \%$ \\
\hline Chevron & $1.31 \%$ & $0.40 \%$ & $0.00524 \%$ \\
\hline Peabody & $1.15 \%$ & $0.13 \%$ & $0.00150 \%$ \\
\hline ConocoPhillips & $0.91 \%$ & $0.40 \%$ & $0.00364 \%$ \\
\hline Rio Tinto & $0.75 \%$ & $0.32 \%$ & $0.00240 \%$ \\
\hline Arch Coal & $0.63 \%$ & $0.18 \%$ & $0.00113 \%$ \\
\hline Anglo American & $0.59 \%$ & $0.41 \%$ & $0.00242 \%$ \\
\hline Contura & $0.54 \%$ & $0.19 \%$ & $0.00103 \%$ \\
\hline Equinor & $0.52 \%$ & $0.12 \%$ & $0.00062 \%$ \\
\hline Consol & $0.50 \%$ & $0.20 \%$ & $0.00100 \%$ \\
\hline Occidental Petroleum & $0.26 \%$ & $0.39 \%$ & $0.00101 \%$ \\
\hline Suncor & $0.22 \%$ & $0.40 \%$ & $0.00088 \%$ \\
\hline Devon & $0.20 \%$ & $0.39 \%$ & $0.00078 \%$ \\
\hline Marathon Oil & $0.19 \%$ & $0.39 \%$ & $0.00074 \%$ \\
\hline Vistra & $0.19 \%$ & $0.29 \%$ & $0.00055 \%$ \\
\hline Ovintiv & $0.18 \%$ & $0.39 \%$ & $0.00070 \%$ \\
\hline Canadian Natural Resources & $0.17 \%$ & $0.39 \%$ & $0.00066 \%$ \\
\hline Hess & $0.16 \%$ & $0.35 \%$ & $0.00056 \%$ \\
\hline Apache & $0.15 \%$ & $0.39 \%$ & $0.00059 \%$ \\
\hline Nacco & $0.13 \%$ & $0.11 \%$ & $0.00014 \%$ \\
\hline EOG & $0.11 \%$ & $0.39 \%$ & $0.00043 \%$ \\
\hline Chesapeake & $0.10 \%$ & $0.17 \%$ & $0.00017 \%$ \\
\hline Teck Resources & $0.09 \%$ & $0.37 \%$ & $0.00033 \%$ \\
\hline Murphy Oil & $0.06 \%$ & $0.19 \%$ & $0.00011 \%$ \\
\hline Noble Energy & $0.06 \%$ & $0.39 \%$ & $0.00023 \%$ \\
\hline Southwestern Energy & $0.04 \%$ & $0.40 \%$ & $0.00016 \%$ \\
\hline Total & $14.39 \%$ & & $0.04698 \%$ \\
\hline
\end{tabular}




\section{2) Self-reported company data approach}

For a second approach to measuring the carbon footprint, I rely on the self-reported data from the Carbon Disclosure Project (CDP) and corporate communications. The CDP data is comprehensive and has greatly improved, but is not without issues. It is self-reported, giving firms an incentive to minimize reported data to improve their public image. However, under-reporting is risky and can be seen as dishonest, somewhat cancelling the benefits of reporting lower emissions. Bae Choi, Lee, and Psaros (2013) show for Australia that larger firms tend to be more accurate in reporting.

Table 2 Scope 3 emissions correlation with potential proxies

\begin{tabular}{lc}
\multicolumn{1}{c}{ Proxy } & $\begin{array}{c}\text { Correlation with scope } 3 \\
\text { emissions }\end{array}$ \\
Scope 2 GHG & 0.74 \\
Employees & 0.65 \\
Sales & 0.62 \\
Assets & 0.61 \\
Market capitalization & 0.52 \\
Profits & 0.51 \\
Scope 1 GHG & 0.46
\end{tabular}

CDP's dataset coverage is incomplete, and not all companies have consistently reported to CDP. I use 2018 CO2 data for $46 \%$ of the companies analyzed; 2017 data for $29 \%$, and earlier data for the rest (some companies have not reported data). When scope $3 \mathrm{CO} 2$ emission data is missing, I use proxies to extrapolate data (scope 3 emissions mainly measure emission from the use of a company's products and its investments). I ran simple correlation tests on seven likely scope 3 emissions correlates to see which one best fits scope 3 emissions in my sample (Table 2). Self-reported scope 2 CO2 emissions is the best match which I use to extrapolate data for companies for which I have scope 3 but not scope 2 data (scope 2 mainly measures the energy needed to run a company). When scope 2 data is unavailable, I use employee count, the second best match. Using employees as a proxy for all missing data also yield similar results. As the correlation used in Table 2 uses few data points, I also use sales figures as a proxy, even though their correlation is only third in Table 2, it is likely to be the most logical correlate with a company's scope 3 data as it is a measure of the use of sold products. Either specification yields results which are within a $10 \%$ range for the impact of the portfolio of the SNB.

Figure 2 shows the OLS fit. Any additional metric ton of scope 2 emissions is associated with 44.8 additional metric tons of scope 3 CO2 emissions. For an additional employee the figure is 4720.15 and for an additional billion in sales the figure is $1,274,958$. I use these numbers for extrapolation. 
Scope 3 emissions extrapolation with Scope 2 emissions (In metric tons of $\mathrm{CO} 2$ )

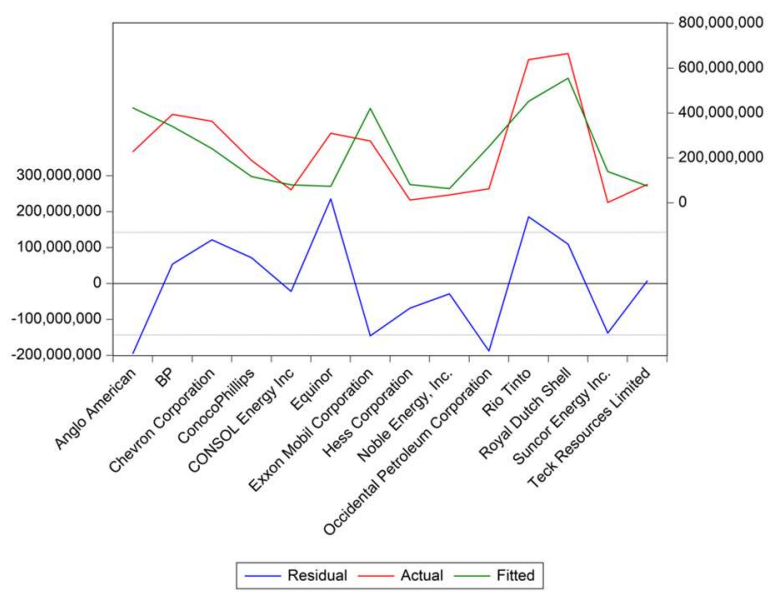

Scope 3 emissions extrapolation with number of employees (In metric tons of $\mathrm{CO} 2$ )

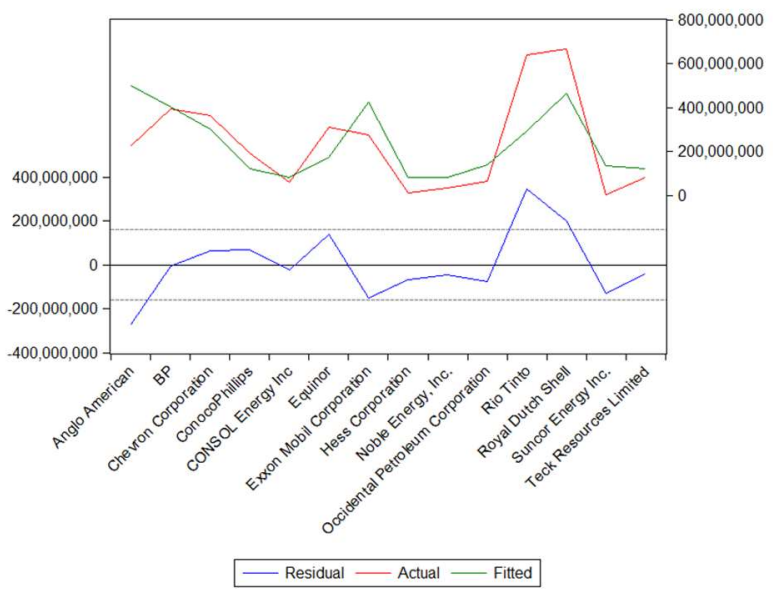

In Table 3, I compute three sums, one with only self-reported data (third column from the right) and two including extrapolated data (last two columns). The SNB's portfolio emissions adjusted for holdings is 11.55 million tCO2e, or $11.95 / 12.73$ with extrapolations. The last figure represents $24 \%$ of Swiss emissions.

It is lower than using the global emissions approach (20.25 previously vs $11.95 / 12.73$ here). The difference is largely due to the way self-reported $\mathrm{CO} 2$ data is collected. The self-reported CDP data might be underestimated in some cases while the data by Griffin (2017) actually estimates CO2 by counting the number of barrels extracted by fossil companies. An example of potential underreporting is the 275.8 million tCO2e reported by ExxonMobil as they imply that the company would have generate $32 \%$ less CO2 than Chevron, when Chevron has sales which are $45 \%$ smaller. It is therefore likely that the ExxonMobil data is underreported and it is unlikely that any firm would have overreported emissions as high emissions reflect negatively on firms. The estimate in the second approach is likely to be an underestimation. 
Table 3 Scope 3 emissions in million tCO2e, self-reported and extrapolated

\begin{tabular}{|c|c|c|c|c|c|c|c|}
\hline Company & $\begin{array}{c}\text { SNB's company } \\
\text { share }\end{array}$ & $\begin{array}{l}\text { Self-reported } \\
\text { scope } 3\end{array}$ & $\begin{array}{c}\text { Scope } 3 \\
\text { (disclosed and } \\
\text { sales } \\
\text { extrapolation) }\end{array}$ & $\begin{array}{c}\text { Scope } 3 \\
\text { (disclosed, scope } \\
2 \text { and employee } \\
\text { extrapolations) }\end{array}$ & $\begin{array}{l}\text { SNB portfolio } \\
\text { share (self- } \\
\text { reported data) }\end{array}$ & $\begin{array}{l}\text { SNB portfolio } \\
\text { share (including } \\
\text { sales } \\
\text { extrapolation) }\end{array}$ & $\begin{array}{l}\text { SNB portfolio } \\
\text { share (including } \\
\text { scope } 2 \text { and } \\
\text { employee } \\
\text { extrapolations) }\end{array}$ \\
\hline Royal Dutch Shell & $0.39 \%$ & 665.6 & 665.6 & 665.6 & 2.60 & 2.60 & 2.60 \\
\hline Rio Tinto & $0.32 \%$ & 638.4 & 638.4 & 638.4 & 2.04 & 2.04 & 2.04 \\
\hline $\mathrm{BP}$ & $0.36 \%$ & 395.0 & 395.0 & 395.0 & 1.42 & 1.42 & 1.42 \\
\hline Chevron & $0.40 \%$ & 364.0 & 364.0 & 364.0 & 1.46 & 1.46 & 1.46 \\
\hline Equinor & $0.12 \%$ & 310.1 & 310.1 & 310.1 & 0.37 & 0.37 & 0.37 \\
\hline ExxonMobil & $0.40 \%$ & 275.8 & 275.8 & 275.8 & 1.10 & 1.10 & 1.10 \\
\hline Anglo American & $0.41 \%$ & 228.3 & 228.3 & 228.3 & 0.94 & 0.94 & 0.94 \\
\hline ConocoPhillips & $0.40 \%$ & 189.1 & 189.1 & 189.1 & 0.76 & 0.76 & 0.76 \\
\hline Canadian Natural Resources & $0.39 \%$ & & $21.9^{*}$ & $89.0 * *$ & & $0.09^{*}$ & $0.35^{* *}$ \\
\hline Teck Resources & $0.37 \%$ & 82.8 & 82.8 & 82.8 & 0.31 & 0.31 & 0.31 \\
\hline Occidental Petroleum & $0.39 \%$ & 63.0 & 63.0 & 63.0 & 0.25 & 0.25 & 0.25 \\
\hline Apache & $0.39 \%$ & & $22.4^{*}$ & $62.7^{* *}$ & & $0.03^{*}$ & $0.24^{* *}$ \\
\hline Consol Energy & $0.20 \%$ & 58.6 & 58.6 & 58.6 & 0.12 & 0.12 & 0.12 \\
\hline Marathon Oil & $0.39 \%$ & & $6.5^{*}$ & $40.5^{* *}$ & & $0.03^{*}$ & $0.16^{* *}$ \\
\hline Noble Energy & $0.39 \%$ & 35.1 & 35.1 & 35.1 & 0.14 & 0.14 & 0.14 \\
\hline Peabody & $0.13 \%$ & & $5.8^{*}$ & $\underline{31.2}^{* * *}$ & & $0.01^{*}$ & $\underline{0.04}^{* * *}$ \\
\hline Devon & $0.39 \%$ & & $8.7^{*}$ & $25.4^{* *}$ & & $0.03^{*}$ & $0.10^{* *}$ \\
\hline Vistra & $0.29 \%$ & & $14.6^{*}$ & $\underline{24.9}^{* * *}$ & & $0.04^{*}$ & $\underline{0.07}^{* * *}$ \\
\hline Contura & $0.19 \%$ & & $2.9^{*}$ & $\underline{20.6}^{* * *}$ & & $0.01^{*}$ & $\underline{0.04}^{* * *}$ \\
\hline Arch Coal & $0.18 \%$ & & $2.9^{*}$ & $18.4^{* *}$ & & $0.01^{*}$ & $0.03^{* *}$ \\
\hline EOG & $0.39 \%$ & & $22.4^{*}$ & $\underline{13.7}^{* * *}$ & & $0.09^{*}$ & 0.05 \\
\hline Hess & $0.35 \%$ & 13.1 & 13.1 & 13.1 & 0.05 & 0.05 & 0.05 \\
\hline Nacco & $0.11 \%$ & & $0.2^{*}$ & $\underline{11.3}^{* * *}$ & & $0.01^{*}$ & $\underline{0.01}^{* * *}$ \\
\hline Chesapeake & $0.17 \%$ & & $11.0^{*}$ & $\underline{10.9}^{* * *}$ & & $0.02^{*}$ & $\underline{0.02}^{* * *}$ \\
\hline Ovintiv & $0.39 \%$ & & $9.1^{*}$ & $\underline{9.7}^{* * *}$ & & $0.04^{*}$ & $\underline{0.04}^{* * *}$ \\
\hline Southwestern Energy & $0.40 \%$ & & $4.1^{*}$ & $\underline{4.4}^{* * *}$ & & $0.02^{*}$ & $\underline{0.02}^{* * *}$ \\
\hline Murphy Oil & $0.19 \%$ & & $3.4^{*}$ & $\underline{3.9}^{* * *}$ & & $0.01^{*}$ & $\underline{0.01}^{* * *}$ \\
\hline Suncor & $0.40 \%$ & 2.1 & & 2.1 & 0.01 & 0.01 & 0.01 \\
\hline Total & & 3321 & 3443 & 3688 & 11.55 & 11.95 & 12.73 \\
\hline
\end{tabular}

Note: Data is self-disclosed or extrapolated from sales $\left(^{*}\right)$, scope $2(* *)$ or number of employees $(* * *)$. See text for explanation. 
Now for a rudimentary counterfactual. What if the SNB invested the value of its holdings in these 27 companies, into Apple, the largest US capitalization. This is unrealistic as it would unbalance the portfolio's risk profile, but it gives a back-of-the-envelope comparison of an alternative portfolio. If the SNB reallocated the $\$ 3.74 \mathrm{bn}$ currently invested in these 27 companies into Apple, it would own an additional $0.24 \%$ of Apple. This investment would generate 0.07 million scope 3 tCO2e instead of 20.25 million tCO2e for the current portfolio (doing the same exercise with Google/Alphabet would generate 0.01 million tCO2e). This would reduce the emissions associated with this $\$ 3.74 \mathrm{bn}$ investment by 99.66\%. And Apple is far from being a low carbon company. But by reallocating this investment into any balanced portfolio excluding oil, gas or coal, the orders of magnitude would be similar. This is only a reallocation of $2 \%$ of the SNB's equity portfolio and $0.4 \%$ of its foreign currency portfolio. Assuming a more balanced approach than this thought experiment, this would not disrupt the risk structure of the portfolio and offset the environmental impact significantly.

\section{Conclusion}

The SNB's portfolio generated at least $38 \%$ of Swiss emissions, the equivalent of all the country's households. By shifting only $2 \%$ of its portfolio, the SNB could reduce its footprint by up to 20.18 million tCO2e without significantly altering the risk profile of the portfolio.

A portfolio reallocation out of these 27 companies into less polluting assets would not reduce greenhouse gas emissions overnight. These shares would be bought by other investors. It would however reduce

their market value if around $0.4 \%$ were sold, which in turn makes borrowing more expensive and reduce CEOs stock option value. And it would send a signal as a public investor, while helping Switzerland reach its Paris Agreement goals, which include reducing emissions from financial assets.

With a more focused investment strategy, the SNB could impact investment decisions of companies. As a public investor, the SNB could also nudge other investors in doing the same to facilitate a green transition. It could follow practices set up by the Norges Bank Investment Management (NBIM) which does not invest in coal and takes an active role to help fossil fuel companies transition towards greener practices (see NBIM 2019).

\section{Bibliography}

Bae Choi, Bo, Doowon Lee, and Jim Psaros. 2013. "An Analysis of Australian Company Carbon Emission Disclosures." Pacific Accounting Review 25 (1): 58-79.

Best, Jacqueline. 2016. "Rethinking Central Bank Accountability in Uncertain Times." Ethics \& International Affairs 30 (2): 215-32.

GHG protocol. 2011. "Corporate Value Chain (Scope 3) Accounting and Reporting Standard", World Resources Institute and World Business Council for Sustainable Development, 
available at https://ghgprotocol.org/sites/default/files/standards/Corporate-ValueChain-Accounting-Reporing-Standard_041613_2.pdf

Griffin, Paul. 2017. "Carbon Majors Report 2017." Carbon Disclosure Project (CDP) report.

Jackson, R. B., P. Friedlingstein, R. M. Andrew, J. G. Canadell, C. Le Quéré, and G. P. Peters. 2019. "Persistent Fossil Fuel Growth Threatens the Paris Agreement and Planetary Health." Environmental Research Letters 14 (12): 121001.

Klooster, Jens van 't, and Clément Fontan. 2020. "The Myth of Market Neutrality: A Comparative Study of the European Central Bank's and the Swiss National Bank's Corporate Security Purchases." New Political Economy 25 (6): 865-879.

Maechler, Andréa M., and Thomas Moser. 2019. "Climate Risks and Central Banks: An SNB Perspective." Official Speech, Geneva.

Norges Bank Investment Management (NBIM). 2019. "Responsible investment 2019", report Nb 6, available at https://www.nbim.no/contentassets/aaa1c4c4557e4619bd8345db022e981e /spu_responsible-investments-2019_web.pdf

Official Monetary and Financial Institutions Forum (OMFIF). 2019. "Global Public Investor Database 2019".

Steininger, Karl W., Christian Lininger, Lukas H. Meyer, Pablo Muñoz, and Thomas Schinko. 2016. "Multiple Carbon Accounting to Support Just and Effective Climate Policies." Nature Climate Change 6 (1): 35-41.

Swiss National Bank. 2015. "Investment Policy Guidelines of the Swiss National Bank (SNB) of 27 May 2004, (as at 1 April 2015)". 